\title{
THEORETICAL AND EXPERIMENTAL RESEARCH IN FUEL CONSUMPTION AT MISCANTHUS RHIZOMES PLANTING
}

\author{
Gheorghe Voicu ${ }^{1}$, Gabriel-Alexandru Constantin ${ }^{1}$, Petru Cardei ${ }^{2}$, Ion Cristian Poenaru ${ }^{1}$ \\ ${ }^{1}$ University Politehnica of Bucharest, Romania; ${ }^{2}$ National Institute of Research-Development for \\ Machines and Installations Designed to Agriculture and Food Industry, Romania \\ ghvoicu_2005@yahoo.com,gabriel_alex99@yahoo.com, petru_cardei@yahoo.com
}

\begin{abstract}
The paper presents original results obtained by the authors in the energy field of the miscanthus plant aggregates, using a four-row planter, equipped with various covering organs. An original mathematical model of fuel consumption in the planting of miscanthus rhizomes is presented, obtained by an original theoreticalempirical method, based on the experimental data obtained with the help of original conception experiences, in correlation with traction resistance of the machine.The experiments performed implied different use of the working organs of the four sections of a miscanthus rhizome planting machine, each section consisting of a hoe ploughshare, but different covering organs (cover plates and a simple metal wheel for compaction, respectively two coating and compaction wheels arranged in V-configuration). The 75 experiments performed had three different working depths $(0.06,0.09$ and $0.12 \mathrm{~m})$, each having its own moving speed. Resulting values for specific fuel consumption were introduced into a program made in Mathcad, and by the least squares method using the mathematical model presented in the paper, the specific fuel consumption coefficients were determined for each of the five types of work organs (ploughshare, cover plates, simple compaction wheel, compaction wheel with wings, respectively the rolling train of the machine).
\end{abstract}

Keywords: miscanthus rhizomes, planting machine, traction force, fuel consumption, correlation.

\section{Introduction}

Study of agricultural aggregates in their energetic space (the set of energetic parameters and their value ranges) is the final stage of researches regarding the way of working, parameters that influence performance and relationships between the parameters involved, as well as between the performance parameters and interaction parameters between the machine and the environment. At this stage, energy consumption for different working regimes is deducted, and, in addition, it is trying to assess the existence of the possible optimal working regimes.

In most researches the main optimization parameters used are: working speed (most often considered constant), working width (where it can change) and the size of the parcels. The most common objective functions are the energy consumption specific to the surface unit, consumption of fuel, production capacity, quality parameters of planting (shape and quantity of soil worked, uniformity of the work depth, uniformity of the distance between the rows, uniformity of the distance between the plants per row, etc.). For miscanthus planting machines such studies are few and the machine is difficult to fit into a more general category of machines already dealt with in the specialty literature. This is due first of all to the used particular system of machine organs and its variants.

Generally, the ploughshare is designed to open a furrow, in which rhizomes (or seeds) are deposited via a guide tube before being partially covered by the soil. The ploughshares used in planting machines differ depending on the type of the soil and working conditions. The most common types of ploughshares are the type hoe, shoe, shovel, chisel, winged chisel, inverted T, or openers with discs. The least energy consuming are the ploughshares with discs, but the gutters are generally narrow [1]. It has been determined that at ploughshares of type hoe, shoe, or shovel [2] the most important parameters that lead to minimum forward resistances are the connection angles, displacement velocity, depth and the width of the ploughshare. Also, the opening force of the furrow increases with the working speed, and the percentage of plant growth depends both on the type of the ploughshare and the working speed. The lowest resistance to soil penetration, draft force and high percentage of plant growth were recorded for a shovel type furrow opener [3].

Papers [4;5] have approached the issue of correlation of the traction force with process parameters at rhizome planting, based on the same way of organizing experiments as in the present paper, concluding that the planting machine with covering/compaction organs in V-configuration has a higher working speed compared to machines equipped with two covering discs and a compaction wheel. Two-disc furrow openers were analysed by Javadi et al. [6], who propose to use a modified 
opener for a better working process, while Solhjouet al. [7] have analysed the soil movement at the opening of the furrow with narrow geometry openings.

The evaluation of several combinations of ploughshares and compaction wheels has been studied by Bahri and Bansal [8]. The authors found that the double disc ploughshare is more suitable for use in unprocessed land, while the ploughshare type hoe was better suited to hard and dry soil conditions due to better soil penetration.The role of compaction wheels is to cover rhizomes (and seeds) with soil and improve the contact with soil. If we suppose to have a field in no-till conditions, the width of the compaction wheel must be equal to or less than the width of the gutter opened by ploughshare, otherwise the compaction wheel will tread on the furrow walls causing insufficient compaction for a good soil contact.A positive effect of compaction wheels with two row ribbing was found, which made better closing of the furrow and better compaction of the soil. Analysis of the rhizome coverage process with a two-disc coating system and a simple compaction wheel was also performed in the paper [9].

Relatively recent studies suggest that to maximize biomass production of $M$. giganteuson the surface in the planting year rhizomes should have about $60-75 \mathrm{~g}$, the planting depth to be of $0.10 \mathrm{~m}$, and rhizomes kept in cold stores as little time as possible [10].

The purpose of our work is to demonstrate (or at least to bring it to the fore) that the experiments in participation of each working organ of the planting machine to the general fuel consumption, or to total forward resistance of the rhizome planting machine can be organized in a way other than the usual one of separate study in the laboratory (soil channel). A mathematical model for determining the fuel consumption has been developed for each of the working organs of a miscanthus rhizome planting machine MPM-4 (designed and manufactured by INMA Bucharest institute, where 4 is the number of rows), depending on the forward resistances encountered by them, for various working conditions in the field, the resulting values being compared to those determined experimentally.

\section{Materials and methods}

Plant miscanthus rhizome machines consist of several sections (their number is equal to the number of rows). Each section is equipped with several work organs, each of which has a wellestablished role in the planting of rhizomes. MPM-4 planting machine sections are mounted on a twowheel metal frame being equipped with a ploughshare, system of distribution of rhizomes to the gutter, respectively with two types of cover organs (not both at the same time). The coating organs used and experienced by us were: 1) two coating discs and a compression metal wheel; 2) two coating wheels and metal compaction, in V-configuration, having the side surface provided with fins (blades).

An overview of a section of the rhizome planting machine is presented in Fig. 1.

a)

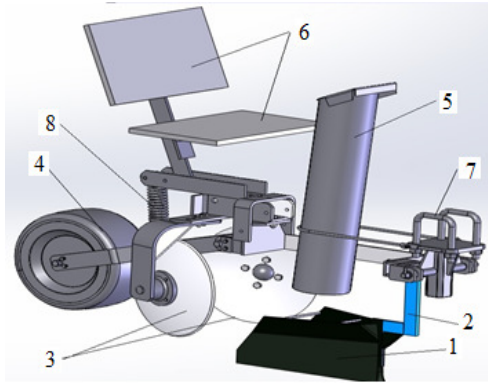

b)

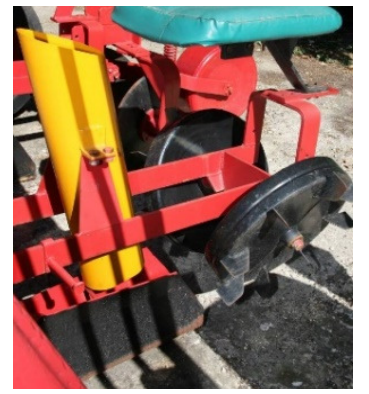

c)

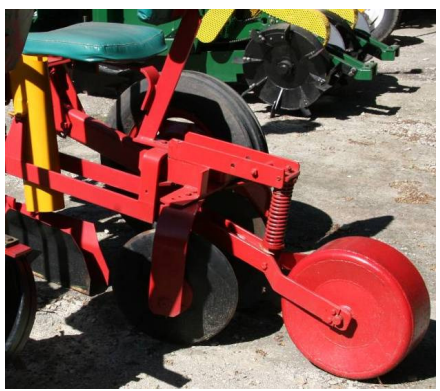

Fig. 1. Parts of MPM-4 machine section for miscanthus planting (a), section with compaction wheels in V-configuration (b) and section with two coating discs and compaction wheel (c):

1 - ploughshare; 2 - ploughshare support; 3 -.cover plates; 4 - compaction wheel; 5 - steering tube; 6 - operator seat; 7 - attachment brackets to the machine frame; 8 - spring for wheel compaction adjustment

The experiments were carried out in several variants of the structure of the four machine sections (with or without all work organs), data processing being made depending on how it is equipped. The equipment categories of the miscanthus rhizome plant are listed in Table 1.

Experiments were performed for three values of the working depth $(0.06,0.09,0.12 \mathrm{~m})$ and were recorded: machine speed (which could not be maintained at constant values due to field conditions), (within $\left.0.83-2.73 \mathrm{~m} \cdot \mathrm{s}^{-1}\right)$, traction force $(3.561-8.527 \mathrm{kN})$, fuel consumption $\left(2.96-5.92 \mathrm{l} \cdot \mathrm{ha}^{-1}\right)$ and the 
power consumed (4.33-22.54 kW). The working depth of the ploughshare also modified the contact surface of the work organs with the soil (see Table 2).

Table 1

Categories of work organs used in field experiments [5]

\begin{tabular}{|c|c|c|c|}
\hline $\begin{array}{c}\text { Experience } \\
\text { index }\end{array}$ & $\begin{array}{c}\text { Number of } \\
\text { active sections }\end{array}$ & Structure of external sections & $\begin{array}{c}\text { Structure of central } \\
\text { sections }\end{array}$ \\
\hline $1-27$ & 2 & $\begin{array}{c}\text { Ploughshare + cover } \\
\text { plates + compaction wheel }\end{array}$ & $\begin{array}{c}\text { Without central } \\
\text { ploughshare }\end{array}$ \\
\hline $28-48$ & 4 & $\begin{array}{c}\text { Ploughshare + cover } \\
\text { plates + compaction wheel }\end{array}$ & $\begin{array}{c}\text { Ploughshare + wheels } \\
\text { with fins, in V }\end{array}$ \\
\hline $49-60$ & 4 & Ploughshare & Ploughshare \\
\hline $61-68$ & 2 & Ploughshare + wheels with fins, in V & - \\
\hline $69-75$ & 2 & Ploughshare + cover plates & - \\
\hline
\end{tabular}

In paper [4] experimental results were presented and their processing regarding the machine pulling force and its variation for the 75 experiments performed (each having other process parameters - depth, working speed, traction force, fuel consumption, power consumption). Average values of the process parameters, for the categories of the experiments mentioned above, are shown in Table 2.

Table 2

Statistical characteristics of the main parameters in five categories of experiments

\begin{tabular}{|c|c|c|c|c|c|}
\hline $\begin{array}{c}\text { Experience } \\
\text { index }\end{array}$ & $\begin{array}{c}\text { Average value of } \\
\text { traction force, } \\
\mathbf{k N}\end{array}$ & $\begin{array}{c}\text { Average fuel } \\
\text { consumption, } \\
\mathbf{l}^{-\mathbf{h a}^{-1}}\end{array}$ & $\begin{array}{c}\text { Average work } \\
\text { speed, } \mathbf{m} \cdot \mathbf{s}^{-\mathbf{1}}\end{array}$ & $\begin{array}{c}\text { Average power } \\
\text { required by the } \\
\text { machine, } \mathbf{k W}\end{array}$ & $\begin{array}{c}\text { Average effective } \\
\text { surface area of } \\
\text { work organs, } \mathbf{~ m}^{\mathbf{2}}\end{array}$ \\
\hline $1-27$ & $4.888 / 1.091^{*}$ & $3.775 / 0.636^{*}$ & $1.870 / 0.538^{*}$ & $9.142 / 3.391^{*}$ & 0.276 \\
\hline $28-48$ & $7.233 / 0.996^{*}$ & $3.924 / 0.586^{*}$ & $1.830 / 0.517^{*}$ & $12.890 / 3.953^{*}$ & 0.428 \\
\hline $49-60$ & $7.590 / 0.556^{*}$ & $4.467 / 0.652^{*}$ & $1.595 / 0.632^{*}$ & $12.086 / 4.838^{*}$ & 0.067 \\
\hline $61-68$ & $4.527 / 0.632^{*}$ & $3.522 / 0.416^{*}$ & $1.786 / 0.527^{*}$ & $8.058 / 2.539^{*}$ & 0.169 \\
\hline $69-75$ & $4.492 / 0.544^{*}$ & $3.171 / 0.183^{*}$ & $1.879 / 0.529^{*}$ & $8.461 / 2.651^{*}$ & 0.171 \\
\hline
\end{tabular}

* standard deviation

In the present paper, the results on specific fuel consumption are presented and how to process them in correlation with the traction force recorded.

The land, on which the experiments were performed, was INMA Bucharest's test field, from the Baneasa area of the capital of Romania, the soil being brown-reddish forest (luvisols from the arable land category). The land was processed before planting by ploughing at $0.25 \mathrm{~m}$, disking and shredding with a disc harrow and levelled with the full cultivating combinatory. Soil moisture at planting, at the depth of $0.12 \mathrm{~m}$, was between 14.3-20.9\%, and resistance to penetration between 0.6-2.2 MPa, for the depth of $0.25 \mathrm{~m}$, the experiments being carried out in two consecutive days.

The results obtained were processed with the statistical functions of Excel program, and correlations between the process parameters for all experiments performed are shown in Table 3.

Table 3

Matrix of correlations of the mean values for the five main working parameters of the aggregate tractor -miscanthus planting machine [5]

\begin{tabular}{|c|c|c|c|c|}
\hline Parameter & Traction force & Fuel consumption & $\begin{array}{c}\text { Working } \\
\text { speed }\end{array}$ & $\begin{array}{c}\text { Average power } \\
\text { consumed }\end{array}$ \\
\hline Traction force & 1 & 0.867 & -0.752 & 0.973 \\
\hline Fuel consumption & 0.867 & 1 & -0.847 & 0.774 \\
\hline Working speed & -0.752 & -0.847 & 1 & -0.58 \\
\hline Average power consumed & 0.973 & 0.774 & -0.58 & 1 \\
\hline
\end{tabular}

The (-) sign in the table shows an inverse proportionality of the parameters and the closer it is to -1 or +1 , the higher the correlation is. Considering the high value of the correlation between the 
experimental values of the traction resistance and consumption, which are the components of the experimental data vector ( 0.867 for the average values of the parameters), to determine specific fuel consumption, depending on the traction resistance of the working organs of the planting machine, relationships of the following form were used:

$$
\left\{\begin{array}{l}
C_{b}(a, v)=\alpha_{b} \cdot R_{b}(a, v) \\
C_{d}(a, v)=\alpha_{d} \cdot R_{d}(a, v) \\
C_{t}(a, v)=\alpha_{t} \cdot R_{t}(a, v) \\
C_{v}(a, v)=\alpha_{v} \cdot R_{v}(a, v) \\
C_{f}(a, v)=\alpha_{f} \cdot R_{f}
\end{array}\right.
$$

where $R_{b}, R_{d}, R_{t}, R_{v},-$ represent the traction resistance due to the ploughshare of the planting section, cover plates, simple compression wheel, respectively the coating and compaction wheels arranged in $\mathrm{V}$, depending on the depth of planting $a$ and speed of work $v$;

$C_{b}, C_{d}, C_{t}, C_{v}$ - the specific fuel consumptions due to the four work organs, and $R_{f}$ the traction resistance of the displacement train (frame with wheels of the machine) and $C_{f}$ fuel consumption due to it; $\alpha_{b}, \alpha_{d}, \alpha_{t}, \alpha_{v}, \alpha_{f}$ - coefficients specific to each type of the working organ (in $1 \cdot \mathrm{ha}^{-1} \cdot \mathrm{kN}^{-1}$ ).

Calculation mode of the participation in the total of the traction resistance for each of the five specific elements of the miscanthus rhizome planting machine was presented in the paper [4].

Specific fuel consumptions, respectively the coefficients $\alpha_{b}, \alpha_{d}, \alpha_{t}, \alpha_{v}, \alpha_{f}$, were determined by minimizing a functional that depends on these parameters (using the least squares method):

$$
\Psi\left(\alpha_{b}, \alpha_{d}, \alpha_{t}, \alpha_{v}, \alpha_{f}\right)=\sum_{i=1}^{N}\left(\Phi\left(R_{b i}, R_{d i}, R_{t i}, R_{v i}, R_{f i}, \alpha_{b}, \alpha_{d}, \alpha_{t}, \alpha_{v}, \alpha_{f}, i\right)-C_{i}\right)^{2}
$$

where

$$
\Phi=\left\{\begin{array}{l}
2\left(C_{b}+C_{d}+C_{t}\right)+C_{f}, \text { for } i=1, \ldots, 27 \\
2\left(C_{b}+C_{d}+C_{t}\right)+2\left(C_{b}+C_{d}+C_{v}\right)+C_{f}, \text { for } i=28, \ldots, 48 \\
4 C_{b}+C_{f}, \text { for } i=49, \ldots, 60 \\
2\left(C_{b}+C_{v}\right)+C_{f}, \text { for } i=61, \ldots, 68 \\
2\left(C_{b}+C_{d}\right)+C_{f}, \text { for } i=1, \ldots, 27
\end{array} .\right.
$$

For each of the 75 experiments performed (at different depths and working speeds) $C_{i}$ represents the actual fuel consumption recorded during the experiments. The index $i$ changes the expression in function $\Phi$ according to the experience index, which means changing the experimental conditions, more precisely the configuration of the rhizomes planting machine.

To minimize functional (2) an algorithm was used, which underlies the method used in the Mathcad program designed to solve the mathematical model. For further details, please, consult [1113]. The solution is sought in order to comply with restrictions and to minimize the interpolated quality parameter $r$ (relation 7). The imposed restrictions have been established in correlation with the usual values of practice, at the end of a rather long string of attempts, respective:

$$
0.0001<\alpha_{b,} 1.5 \alpha_{v}<\alpha_{d}, 1.1 \alpha_{t}<\alpha_{v}, 0.0001<\alpha_{t}, \alpha_{f}<\alpha_{b}
$$

and the starting point has coordinates:

$$
\alpha_{b}=0.0001515, \alpha_{d}=0.0001, \alpha_{v}=0.0001, \alpha_{t}=0.0001, \alpha_{f}=0.000167 .
$$


After searches made, the following solution was obtained:

$$
\alpha_{b}=0.0006994, \alpha_{d}=0.000165, \alpha_{v}=0.00011, \alpha_{t}=0.0001, \alpha_{f}=0.0006998,
$$

which had a mean square error of $2.682 \%$, as a measure of interpolation accuracy, given by the relationship:

$$
r=\frac{\sqrt{\sum_{i=1}^{N}\left(\left(R_{b i}, R_{d i}, R_{t i}, R_{v i}, R_{f i}, \alpha_{b}, \alpha_{d}, \alpha_{t}, \alpha_{v}, \alpha_{f}, i\right)-C_{i}\right)^{2}}}{N \bar{C}} 100(\%),
$$

where $\bar{C}$ is the mean value of experimental consumption;

$N$ the number of experimental data, in our case this is 75 .

\section{Results and discussion}

The experimental data obtained and the mathematical model presented above were used in calculating the fuel consumption for each type of the work organ, respectively for graphical drawing of the consumption distribution for all 75 experiments (organized in the five categories, according to Table 1 and Table 2), also to identify the contribution of each work organ to the general machine specific consumption.

In Fig. 2 graphically the fuel consumption experimentally determined is presented, in line with the calculated on the basis of the traction resistance with the above model.

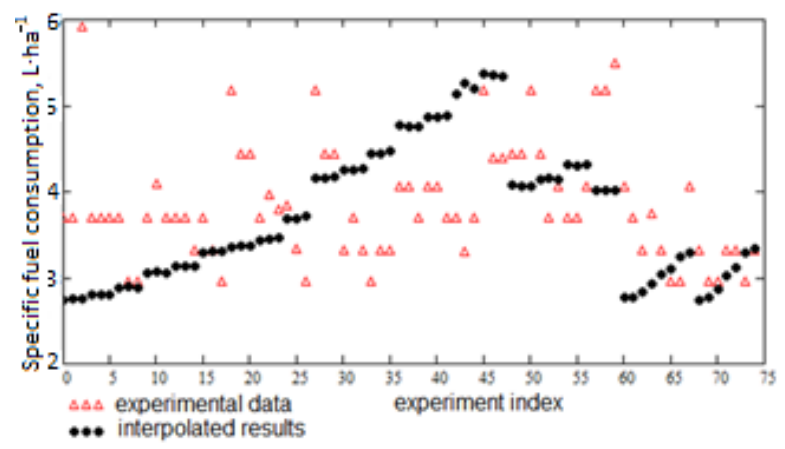

Fig. 2. Distribution of experimental and interpolated consumption for all experiments

To get a quick and general information on the variation of the specific consumption with the speed of work, the consumption functions for each work variant of the miscanthus plant were graphically represented on each component of the working stations (Fig. 3 and Fig. 4).

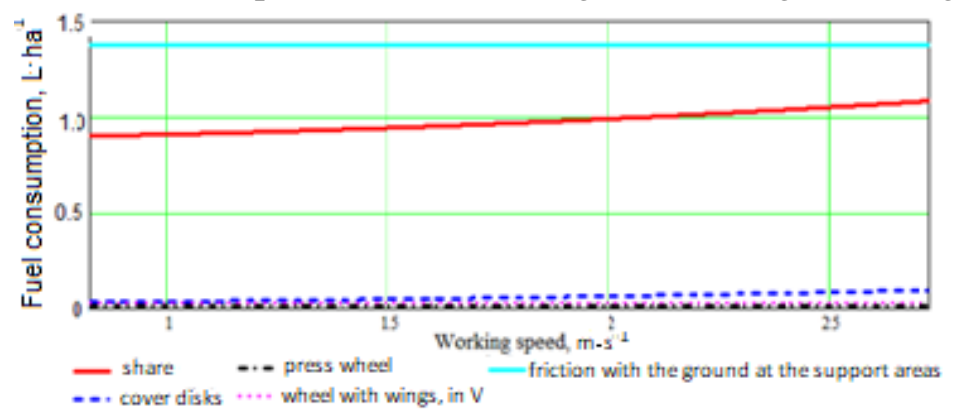

Fig. 3. Contribution of each component of miscanthus plant in specific fuel consumption (l.ha $\left.{ }^{-1}\right)$, variation with working speed for working at depth of $0.12 \mathrm{~m}$

It is noticed that, due to the working hypotheses, consumptions corresponding to the ploughshare, cover plates and wheels with fins in $\mathrm{V}$ increase with increasing of the work speed, while the consumption components due to the compaction wheel and the friction between the ground and the wheels of the drivetrain are constant. Therefore, critical points of fuel consumption, on components or globally, will not be found. This statement proves easy for theoretical using and explaining consumption relationships (1). 


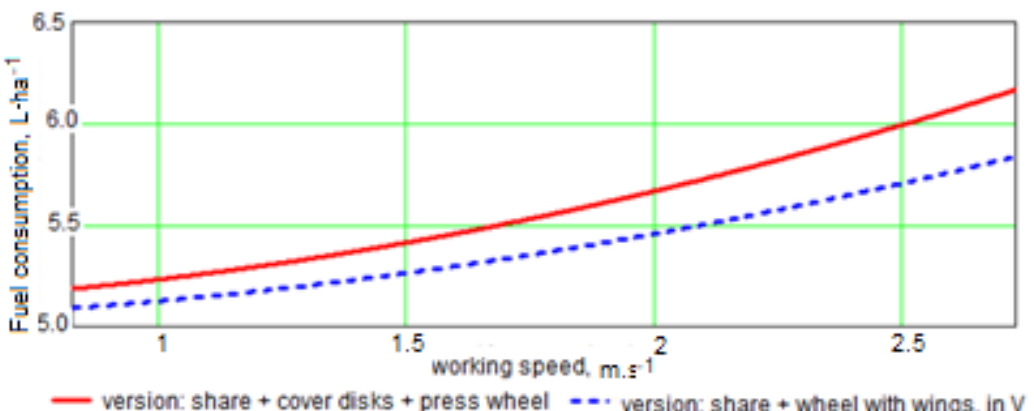

Fig. 4. Fuel consumption variation for two versions of miscanthus rhizome planting machine with working speed for constant working depth of $0.12 \mathrm{~m}$

The graphs show that the fuel consumption for the machine's own displacement has a relatively constant value (about $1.41 \cdot \mathrm{ha}^{-1}$ ), while running a single compaction wheel, the fuel consumption is very low (about $0.05 \mathrm{l} \cdot \mathrm{ha}^{-1}$ ), being slightly larger for the rolling of V-configuration compaction/covering wheels, but also constant, regardless of the work speed. Instead, specific fuel consumption, for a working depth of $0.12 \mathrm{~m}$, grows from about $0.91 \cdot \mathrm{ha}^{-1}$ at about $1.1 \mathrm{l} \cdot \mathrm{ha}^{-1}$, for the working speeds up to $3 \mathrm{~m} \cdot \mathrm{s}^{-1}$.

The comparative variation in the specific consumption of the two variants of the miscanthus plant machine is shown in Fig.4. It can be seen that in both variants the fuel consumption increases with the working speed and the variant with wheels with fins arranged in $\mathrm{V}$ is more economical. It is also noted that the consumption difference between the two variants increases with increasing the work speed, but this configuration is valid within the experimental limits of the speed and working depth.Thus, for the working depth of $0.12 \mathrm{~m}$, the fuel consumption increases from about 5.1, respective $5.2 \mathrm{l} \cdot \mathrm{ha}^{-1}$, at about 5.8, respective $6.21 \cdot \mathrm{ha}^{-1}$, for the two versions of the MPM-4 planting machine.

Variation with the working speed of total fuel consumption, for the working version of the planting machine with the ploughshare, cover discs and a compression wheel, at depth of $0.12 \mathrm{~m}$, is shown in Fig. 5, each individual fuel consumption being multiplied by four times, less fuel consumption to drive the machine (of the running organs).

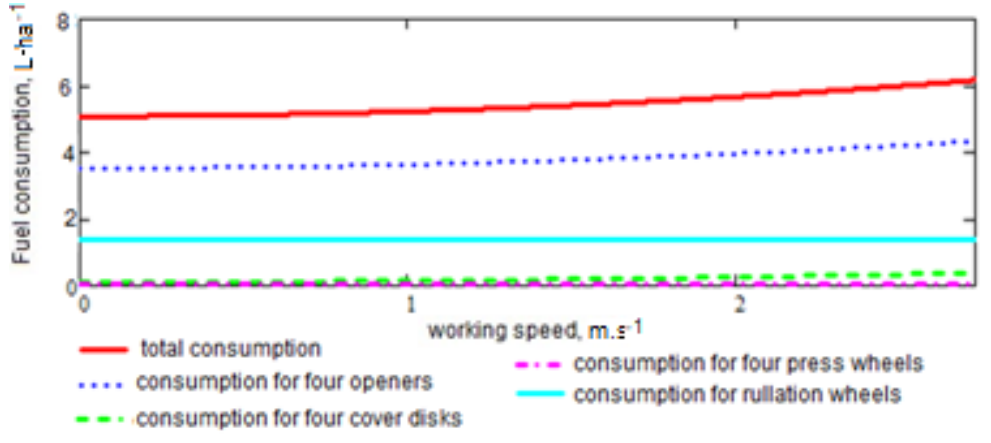

Fig. 5. Fuel consumption for planting machine with sections with ploughshare + cover plates + compaction wheel, depending on the speed of the machine, at work depth of $0.12 \mathrm{~m}$

\section{Conclusions}

The mathematical model applied in our investigation led to identification of the fuel consumption on components of the planting machine, respectively to the variation of these consumptions with the work-depth, respectively with the operational speed. The computational program developed in Mathcad allows, also, determining the variation of the fuel consumption with the working depth, the two parameters being, obvious, directly proportional.

From the data presented in the paper, it turned out that the ploughshare of the planting machine is the largest fuel consumer (between 0.9-1.1 1.ha ${ }^{-1}$ for one ploughshare), and the total consumption of rhizome planting machines depends on how the machine sections are equipped, having the values between 5.2-6.1 1.ha ${ }^{-1}$, for the most complex equipment (sectionswith ploughshare + covering 
discs + compaction wheel), at the highest work depth $(0.12 \mathrm{~m})$, depending on the speed of the machine. Still, the most economical option of the equipment proved to be the one with simple planting sections, only with a ploughshare and compaction/covering wheels with fins, in V-configuration. It is worth mentioning that choosing one or other equipment options depends also on the degree of processing of the soil, so that rhizomes are properly covered.

\section{References}

[1] Seidi E., Effects of geometry of disk openers on seed slot properties, World Academy of Science, Engineering and Technology, 72, 2012, pp. 83-87.

[2] Chaudhuri D., Performance evaluation of various types of furrow openers on seed drills - A review, Journal of Agricultural Engineering Research, vol. 79, 2001, pp. 125-137.

[3] Altuntas E. et al., Assessment of different types furrow openers using a full automatic planter, Asian Journal of Plant Sciences, 5, 2006, pp. 537-542.

[4] Poenaru I.C., Cardei P., VoicuGh., Paraschiv G., Dinca M., Vladut V., Matache G., Researches in the field of the energetics of the miscanthus planter. (1) - Determination of the traction force, U.P.B. Sci. Bull., Series D, Vol. 77, Iss. 1, 2015, pp. 245-256.

[5] Voicu G., Dinca M., Matache G., Poenaru I. C., Cardei P., Voicu P., Vladut V. Researches regarding organization of the experiments for energetic characteristics determination when using Miscanthus planter, 4rd International Conference on Thermal Equipment, Renewable Energy and Rural Development - TE-RE-RD, House Publishing Politehnica Press, 2015, pp. 405-410.

[6] Javadi A., Seyedi E., Mohamadigol R., Shahidzadeh M., Effect of a Modified and Common Disc Openers on Soil Failure and Forces using for Direct Planting, Global Jo. of Medicinal Plant Research, 1(1), 2012, pp. 26-32.

[7] Solhjou A., Fielke J.M., Desbiolles J., Effect of narrow opener geometry on lateral surface soil movement and implications for no-till seeding, 5th World Congress on Conservation Agriculture, incorporating 3rd Farming Systems Design Conference, Brisbane, Australia, 2011, pp. 167-168.

[8] Bahri A., Bansal R.K., Evaluation of different combinations of openers and press wheels for notill seeding, Proceedings of an international seminar of the 3rd section of the International Commission on Agricultural Engineering, held in Rabat, Morocco, 1992, pp. 87-108.

[9] Voicu Gh., Poenaru I.C., Paraschiv G., M.N. Dinca, Vladut V., Theoretical modelling of working process of covering devices to miscanthus rhizomes planters, Proceedings of the nd 42 International Symposium "Actual Tasks on Agricultural Engineering", Croatia, Opatija, 2014, pp. 137-148.

[10]Pyter R.J., Dohleman F.G., Voigt T., Effects of rhizome size, depth of planting and cold storage on Miscanthus $\mathrm{x}$ giganteus establishment in the Midwestern USA, Biomass and Bioenergy, 34(10), 2010, pp. 1466-1470.

[11] Winston W.L., Goldberg J.B., Operations research: Applications and algorithms, Belmont, CA: Thomson/Brooks/Cole, 2004.

[12] Polak E., Optimization - Algorithms and Consistent Approximations, NYork, Springer Verlag, 1997.

[13] Gill P., Murray W., Wright M., Practical Optimization, San Diego, Academic Press, 1981. 